\title{
AVALIAÇÃO DO POTENCIAL INTERPRETATIVO DA TRILHA DO JEQUITIBÁ, PARQUE ESTADUAL DOS TRÊS PICOS, RIO DE JANEIRO
}

\section{Evaluation of the interpretative potential of Jequitibá Hiking Trail, Parque Estadual dos Três Picos, Rio de Janeiro, Brazil}

Silvia Marie Ikemoto

Especialista Ambiental da Coordenadoria de Recursos Hídricos (CRHi), Secretaria de Estado do Meio Ambiente

São Paulo / SP - Brasil silviami@ambiente.sp.gov.br

Moemy Gomes de Moraes Professora Adjunta do Departamento de Biologia Geral, Universidade Federal de Goiás Instituto de Ciências Biológicas

Goiânia / GO - Brasil. moemy@icb.ufg.br

Vivian Castilho da Costa Professora Visitante (Adjunta) do Instituto de Geografia (IGEOG), Universidade do Estado do Rio de Janeiro (UERJ) Departamento de Geografia Física Rio de Janeiro / RJ - Brasil vivianuerj@gmail.com

Artigo recebido para publicação em 19/05/2009 e aceito para publicação em 23/11/2009

RESUMO: O presente estudo avaliou o potencial da trilha do Jequitibá, Parque Estadual dos Três Picos (RJ), para a sensibilização e conscientização dos seus usuários através da Interpretação Ambiental. Foram utilizadas as metodologias de caracterização biofísica da trilha, avaliação da trilha quanto a Interpretação Ambiental e o Índice de Atratividade dos Pontos Interpretativos (IAPI). A trilha do Jequitibá foi caracterizada como de leve dificuldade, curto percurso, com design apropriado para pedestres, sendo os impactos decorrentes do uso considerados mínimos ou controlados. Através do IAPI, pôde-se concluir que é uma trilha altamente atrativa, dotada de uma multiplicidade de recursos interpretativos. Apesar de possuir pontos de interpretação consensuais, estes enfatizam conteúdos biológicos e ecológicos em detrimento dos de cunho histórico e cultural, além de não apresentar roteiros temáticos de interpretação definidos. Embora não atenda a todos os pressupostos da Interpretação Ambiental, a trilha do Jequitibá pode ser considerada com caráter e potencial interpretativo, no entanto, os aspectos frisados devem ser trabalhados de forma a implementar e desenvolver plenamente a Interpretação Ambiental.

Palavras-chave: Trilhas interpretativas.Unidades de Conservação. Índice de Atratividade dos Pontos Interpretativos. Interpretação ambiental.

ABSTRACT: The present research evaluated the potential of Jequitibá Hiking Trail for the visitor sensitization and 
awareness through Environmental Interpretation. Several methodologies were used like biophysical characterization, evaluation of environmental interpretation aspects and Interpretative Points Attractiveness Index (IPAI) of the trail. The Jequitibá Hiking Trail was characterized as light, concerning the level of difficulty, with a short route, with appropriated design for pedestrians, and the impacts of public use were considered insignificant or managed. Through IPAI, it was possible to conclude that it's a highly attractive trail, endowed with several interpretative resources. Despite having consensual points of interpretation, which emphasize ecological and biological contents at the expense of the historical and cultural contents, thematic scripts for interpretation are lacking. Although not reaching all Tilden's assumptions for Environmental Interpretation, Jequitiba Hiking Trail can be seen with character and potential for interpretation, however, the stressed aspects should be worked in order to fully implement and develop Environmental Interpretation.

Keywords: Interpretative trails. Conservation Units. Interpretative Points Attractiveness Index. Environmental Interpretation.

\section{INTRODUÇÃO}

Pela riqueza de seus biomas e a sua diversidade de paisagens, o Brasil apresenta um vasto conjunto de áreas naturais com grande potencial para fortalecer o ecoturismo do país, e no intuito de possibilitar o Uso Público e a visitação concomitantemente à conservação do patrimônio natural, muitas dessas áreas constituem Unidades de Conservação (UC's). O planejamento e gestão da visitação em áreas protegidas têm como grande desafio compatibilizar as demandas de uso dos recursos ambientais com os pressupostos de conservação ambiental, em áreas de elevado valor patrimonial em biodiversidade. Os ecossistemas são susceptíveis a serem comprometidos com a presença do visitante: lixo, pisoteio, barulho excessivo, fluxo acima da capacidade de carga são exemplos de fatores causadores de efeitos negativos (IKEMOTO, 2008, p. 3).

O ordenamento da visitação e a Educação e Interpretação Ambiental (IA) têm, nesse contexto, papel fundamental em direcionar as ações do homem sobre o território de forma a minimizar os impactos ambientais através do monitoramento e manejo dos recursos naturais e a sensibilização dos visitantes e da comunidade do entorno. Além disso, segundo Hanai e Netto (2006, p. 211), programas estruturados de visitação, com roteiros interpretativos adequados, não só promovem a conscientização ambiental, como enri- quecem a experiência de visitação na natureza, satisfazendo as expectativas dos visitantes e auxiliando na valorização dos patrimônios naturais e culturais existentes.

A Interpretação Ambiental, dessa forma, vem ganhando progressivo destaque na gestão de áreas protegidas. Segundo Projetos Doces Matas (2002, p. 13), a IA passou a ter relevância para o planejamento e gestão em UC's a partir da década de 70, momento no qual houve um aumento do interesse pelas atividades recreativas em áreas públicas, sobretudo os Parques Nacionais. Assim, os programas de Interpretação Ambiental passaram, então, a integrar os Planos de Manejo das UC's. No Brasil, a IA é atualmente respaldada nas “Diretrizes para Visitação em UC's” (BRASIL, 2006), documento que apresenta um conjunto de princípios, recomendações e normas a fim de ordenar a visitação em UC's e reitera a importância da visitação como vetor de desenvolvimento local e regional e também como ferramenta de sensibilização da sociedade através da IA.

Embora a relevância dessas ações seja considerada uma meta importante a ser alcançada entre os administradores, parceiros e órgãos ambientais, "no Brasil, a experiência com a implantação de programas educativos e interpretativos em áreas naturais protegidas, principalmente em trilhas interpretativas, é recente e continua restrita" (VASCONCELLOS, 1998, p. 1). 
Segundo Irving (2002, p. 59), a carência de dados publicados ou sistematizados sobre as áreas naturais protegidas constitui uma barreira para a correta compreensão de seus recursos ambientais, culturais e socioeconômicos, e conseqüentemente, para a promoção da Educação e Interpretação Ambiental. CeballosLascuráin (1996, apud FRANCO, 2000, p. 78) por sua vez, discute sobre a deficiência de infra-estrutura adequada para a Interpretação Ambiental nos Parques Brasileiros, e aponta como prováveis razões o desconhecimento dos gestores sobre a Interpretação Ambiental e seus benefícios potenciais; o desconhecimento das diversas técnicas e ferramentas de interpretação; a deficiência de recursos humanos capacitados e a falta de estudos e dados locais que permitam planejar e implementar programas de Interpretação Ambiental.

Em função da relevância do tema e da lacuna de informações e estudos sobre a IA, realizou-se no presente estudo a avaliação do potencial interpretativo da trilha do Jequitibá no Parque Estadual dos Três Picos (PETP), RJ, através do Î́ndice de Atratividade de Pontos Interpretativos (IAPI), levando também em consideração a caracterização e adequação de seu percurso e o inventário de seus atrativos biofísicos, sócioculturais e históricos. Através da análise dos dados obtidos, buscou-se identificar deficiências quanto à interpretação, propor medidas mitigadoras e possíveis soluções, e contribuir para a efetiva elaboração e implementação de um Programa de Interpretação Ambiental no PETP.

\subsection{Interpretação Ambiental}

Embora tenha vários conceitos, a IA é um termo de fácil e clara compreensão. Segundo Tilden (1977, p. 8, tradução nossa), a Interpretação Ambiental é

[...] uma atividade educativa que se propõe revelar significados e inter-relações por meio de uso de objetos originais, do contato direto com os recursos e de meios ilustrativos, em vez que simplesmente comunicar informação literal.

Segundo Projeto Doces Matas (p. 22), a Edu- cação Ambiental (EA) tem caráter contínuo, podendo ser trabalhada em diversas instâncias, formais ou nãoformais, enquanto a Interpretação Ambiental é projetada para um momento específico e de curta duração, em ambientes não-formais, representando ainda

[...] uma alternativa para sensibilizar os visitantes neste curto espaço de tempo disponível em que se encontra em contato com o ambiente natural, na tentativa de aproximá-lo deste meio e finalmente torná-lo mais sensível às questões ambientais relevantes para a conservação da natureza tanto no ambiente natural como no urbano (TALORA et al., 2006, p. 10).

Apesar de não ser um termo amplamente difundido como a "Educação Ambiental”, a Interpretação Ambiental vem ganhando crescente espaço em programas educacionais vinculados ao turismo, uma vez que possui caráter simultaneamente educativo e recreativo. Segundo Corrêa (2006), é comumente realizada em visitas orientadas sobre os patrimônios histórico, artístico, cultural e natural, tais como áreas naturais protegidas (unidades de conservação), museus, coleções (artísticas, botânicas, ou zoológicas), empresas e hotéis-fazenda. Através da Interpretação Ambiental, busca-se explorar os recursos do ambiente a fim de informar e sensibilizar o visitante para a conservação desses patrimônios.

As atividades interpretativas, apesar de não serem pré-definidas ou claramente delineadas, possuem princípios que as norteiam e as permitem caracterizá-las como de cunho interpretativo. Tilden (op. cit), considerado um dos pioneiros do estudo da interpretação, formulou os seguintes princípios quanto a IA:

- Seu objetivo não é exatamente o aprendizado, mas sim buscar sensibilizar o visitante e estimular a sua curiosidade e seu interesse.

- É uma arte que combina com muitas outras artes, além de se basear nos conceitos científicos. Para atingir e tocar o visitante, a interpretação deve ser prazerosa e clara, utilizar uma linguagem simples e se apropriar de di- 
versos recursos para a transmissão da informação, tais como sons, música, histórias, placas, figuras, jogos, dinâmicas, movimento, humor e vídeo.

-É de suma importância estabelecer relações entre o que está sendo interpretado com o cotidiano ou a experiência do visitante, permitindo que este se identifique com os temas abordados. Dessa forma, é possível sensibilizar e tornar a interpretação relevante e significativa ao visitante.

- Não se deve limitar na transmissão de informações e conteúdos. Ela deve revelar aquilo que não está explícito, tais como as relações de interdependência, os diferentes níveis de percepção de um mesmo fenômeno ou ambiente e os significados do tema trabalhado. Além disso, provocar a reflexão e o pensamento crítico do visitante, despertando o interesse e comprometimento do mesmo com local visitado e o meio ambiente.

- A Interpretação Ambiental e o planejamento da atividade devem, portanto, ser diferenciadas em função do público alvo, pois as vivências e experiências de cada visitante são distintas.

- Na interpretação os temas devem ser trabalhados de forma holística e interligada, de forma a ressaltar as inter-relações existentes entre os elementos que compõem o meio ambiente.

Ainda segundo o autor, a organização e planejamento permitem que a mensagem seja transmitida de forma direcionada, e o trabalho em temáticas (mensagem com início, meio e fim) torna claro ao público o objetivo da interpretação. Dessa forma, otimizam-se as atividades, reduzindo esforços e evitando a dispersão do visitante.

\subsection{A Interpretação Ambiental e as Unidades de Conservação (UC’s)}

A Interpretação Ambiental é reconhecida como estratégica dentro do planejamento e manejo das Unidades de Conservação pela sua importância educativa e social. No entanto, baseando-se nos princípios de Tilden (op. cit.), a Interpretação Ambiental pode ser considerada incipiente na maior parte das UC's brasileiras. Apesar de muitas das vezes oferecerem atividades como palestras, passeios em trilhas e outras atividades recreativas ou educativas, essas, na maior parte das vezes, não estão organizadas em torno de um tema interpretativo e ainda não possuem flexibilidade de forma a atender tipos diferenciados de público. Embora sejam agregados alguns valores sobre a proteção ambiental, as informações são trabalhadas de maneira fragmentada e desassociada do cotidiano do visitante.

A publicação das Diretrizes para Visitação em UC's (BRASIL, op. cit.), nesse contexto, contribui para a promoção da IA, estabelecendo parâmetros para a mesma. Segundo o documento, o projeto de interpretação deve ser elaborado de forma participativa, envolvendo a sociedade local, e por uma equipe multidisciplinar, sendo uma ferramenta de minimização dos impactos negativos naturais e culturais. Além disso, deve também utilizar uma linguagem acessível ao conjunto dos visitantes, levar em conta os objetivos gerais e específicos da UC, e ser fundamentada em informações consistentes sobre aspectos naturais e culturais locais, visto a particularidade de cada localidade.

Segundo Sharpe (1982) e Silva (1996), para o desenvolvimento de um programa de Interpretação pleno em uma UC é necessário levar em consideração diversos fatores, dentre eles: a identificação do público alvo, ou seja, a caracterização do perfil do visitante, sua motivação e expectativas em relação à UC; definição clara dos objetivos da interpretação na instituição; realização do inventário interpretativo dos recursos locais, gerando dados estratégicos; a escolha subseqüente dos meios e técnicas apropriadas para o público da UC; e a avaliação dos resultados através do monitoramento, garantindo o aperfeiçoamento e a adequação do programa de Interpretação Ambiental.

Em Unidades de Conservação, a Interpretação Ambiental pode ser desenvolvida a partir de diver- 
sos meios, tais como as trilhas interpretativas, o Centro de Visitantes, coleções de fauna e flora, vídeos, painéis e pôsteres, palestras, entre outros (Projeto Doces Matas, op. cit.). No entanto, as trilhas constituem o grande alvo da visitação e da Interpretação Ambiental, uma vez que são as únicas vias de acesso possíveis de serem construídas e mantidas nas UC's, sendo o espaço de interação entre o visitante e o meio ambiente natural. As trilhas podem ser caracterizadas de duas formas, segundo as normas internacionais (LIMA, 1998, p. 41):

I. Trilhas de interpretação de caráter educativo, pois consistem em instrumentais pedagógicos, podendo ser: (1) auto-interpretativa ou autoguiada; (2) monitorada simples ou guiada; (3) com monitoramento/guia associado a outras programações. O percurso deve ser de curta distância, onde buscamos otimizar a compreensão das características naturais e/ou construídas da sequencia paisagística determinada pelo traçado [...].

II. Trilhas cênicas [...], isto é, trilhas que enfocam aspectos e atributos culturais, históricos, estéticos, etc. Possuem longas distâncias e grandes extensões, sendo consideradas de caráter recreacional [...].

Uma trilha interpretativa bem concebida deve ser curta e com poucos, mas significativos pontos de parada/interpretação. Percursos longos tornam-se cansativos e monótonos, e o excesso de paradas prolonga ainda mais o tempo de percurso, saturando o visitante. Os pontos de parada e interpretação devem ser atrativos e bem delimitados, devendo ser a trilha alargada para comportar simultaneamente o grupo de visitantes sem prejudicar a visibilidade dos atrativos ou da explicação do condutor. Segundo Projeto Doce Matas (op. cit., p. 89), recomenda-se uma extensão máxima de 1,5km e percurso de 45 minutos para trilhas interpretativas, nas quais o objetivo é despertar e manter o interesse do visitante, apresentando grande diversidade de elementos ao longo de seu percurso, não devendo ser visualmente monótono.

As trilhas, uma vez bem planejadas e maneja- das, além de cumprirem a sua função utilitária, permitem o contato e recreação da sociedade e possuem enorme potencial educativo, podendo contribuir para a sensibilização e a conscientização ambiental através de um programa adequado de IA. Dessa forma, são instrumentos de grande importância para o planejamento e manejo da atividade turística e conservação dos recursos ambientais, sendo caracterizadas e analisadas de forma mais aprofundada no presente trabalho, dentre os meios de Interpretação Ambiental.

\section{Caracterização da Área de Estudo}

O Parque Estadual dos Três Picos (PETP) foi criado através do Decreto Lei $n^{\circ}$. 31.343 de 05 de junho de 2002 (RIO DE JANEIRO, 2002), e segundo Campos (2007), constitui a maior UC Estadual do Rio de Janeiro, com uma área total de 46.350 hectares, Silva Jardim, Guapimirim, Teresópolis e Cachoeiras de Macacu (FIG. 1). O Parque foi recentemente ampliado por meio do Decreto Estadual $n^{\circ} 41.990$ de 12 de agosto de 2009 (RIO DE JANEIRO, 2009), apresentando atualmente a área total de 58.790 hectares.

Devido a sua expressiva extensão e a grande variação altimétrica, com cotas entre 100 e 2.330 m, a UC abriga diversas paisagens de grande beleza cênica e possui elevados níveis de biodiversidade. A proximidade do Parque aos grandes centros urbanos, como Niterói e Rio de Janeiro, e sua conexão estratégica com o circuito turístico serrano (Nova Friburgo, Teresópolis e Petrópolis) corroboram para a sua grande potencialidade e vocação educativa e ecoturística. Apesar de sua relevância ecológica, sócio-econômica e ambiental regional, em função de sua recente criação, o PETP ainda possui poucos dados e trabalhos científicos desenvolvidos, que são de fundamental importância para fornecer subsídios às tomadas de decisão e elaboração de programas e projetos. Dessa forma, por sua importância e pela ausência de dados ou programas específicos para o Uso Público e Educação Ambiental, uma das principais trilhas do PETP foi escolhida como objeto desse estudo.

As características da trilha do Jequitibá, de curta distância e de fácil nível técnico, aliado à presença de fortes atrativos como o exemplar de jequitibá-rosa (Cariniana legalis Mart.), estimado em mil anos de 


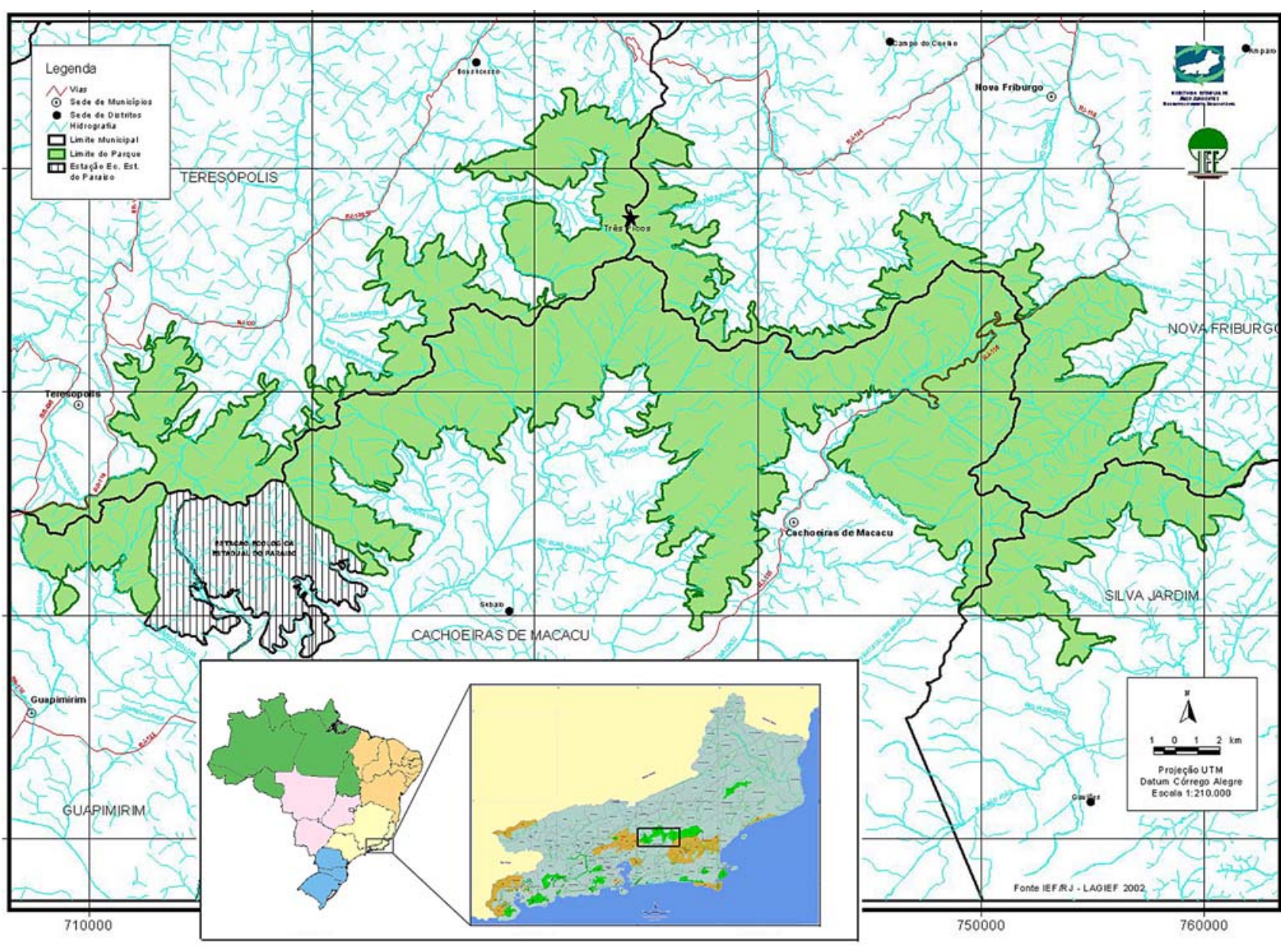

FIGURA 1: Mapa do Parque Estadual dos Três Picos (PETP).

Fonte: Instituto Estadual de Florestas do Rio de Janeiro (IEF/RJ), 2002 apud Ikemoto, 2008.

idade, tornaram a mesma o principal alvo do trabalho de educação e Interpretação Ambiental da UC, sendo selecionada como objeto de estudo dentre outras do sistema de trilhas do PETP.

\section{Metodologia}

\subsection{Caracterização biofísica da trilha interpretativa}

A caracterização da trilha do Jequitibá teve como objetivo determinar suas características gerais, os impactos ambientais nela presentes, sua adequação quanto ao design para diferentes tipos de público e o seu grau de dificuldade, avaliando sua adequação para a Interpretação Ambiental. A trilha foi caracterizada ambientalmente por uma adaptação da metodologia de Takahashi (2001) através da análise do corredor, ou seja, através da coleta de dados físicos e ambientais por locais de amostragem ao longo de seções equidistantes ao longo da trilha. Assim sendo, a trilha foi divida em seções equidistantes de $10 \mathrm{~m}$, e em cada seção, foram colhidos dados referentes aos indicadores de qualidade ambiental.

Para a medição da distância parcial e total da trilha utilizou-se a trena de fita de 50 metros. Cuidados foram tomados de forma a minimizar a imprecisão da medição, tais como manter a fita rente ao solo, respeitar o traçado da trilha e contabilizar as áreas com degraus. Os dados coletados nas seções foram armazenados em fichas de campo (QUADRO 1), sendo medidos ou contabilizados os seguintes parâmetros, segundo metodologia adaptada de Costa (2006):

- Largura (Lrg) - medida (em metros) a ser tomada entre duas estacas de madeira fincadas nas extremidades da trilha com auxílio de trena; 
- Declividade paralela (Dpl) - medida (em graus) a ser tomada ao longo da trilha, no sentido de caminhamento com auxílio do clinômetro;

- Declividade perpendicular (Dpp) - medida (em graus) a ser tomada no sentido transversal de caminhamento da trilha com auxílio do clinômetro;

- Altimetria (Alt) - medida (em metros) da altitude do local selecionado através do uso do altímetro;

- Número de bifurcações (Nbi) - medida do número de bifurcações existentes nas proximidades da trilha.

- Revestimento do solo - foi avaliado pela análise visual local a área (em cm) do corredor da trilha que apresenta: solo exposto (SE), ou seja, sem vegetação; cobertura vegetal viva $(\mathbf{C V})$; serrapilheira (litter - Lit) e/ou presença de afloramento rochoso (AR).
- Lixo (Lx) - número de fragmentos residuais de material inorgânico (latas, sacos plásticos, garrafas pet, etc.) encontrados na trilha e seu entorno, na área delimitada para a coleta de dados.

- Vandalismo (Vd) - presença de fogueiras, desmatamento, pichações em rochas ou árvores, animais mortos ou vestígios de caça, etc.

- Erosão (Er) - análise visual da presença de algum dos tipos de erosão no solo: erosão lateral (Lat) - provocada pela drenagem pluvial), erosão laminar (Lam - superficial) e erosão em sulcos (SC) - mais profunda, como ravinamentos) nas seções da trilha.

- Proximidade de drenagem (Dre) - presença de corpos d'água (rios) nas laterais, cruzando ou próximo da trilha.

- Calhas ou canaletas de drenagem (CA) - presença de canais de drenagem ou calhas pluviais nas laterais ou cruzando a trilha.

\begin{tabular}{|c|c|c|c|c|c|c|c|c|c|c|c|c|c|c|c|}
\hline \multirow{2}{*}{\multicolumn{3}{|c|}{ FICHA DE CAMPO }} & \multicolumn{5}{|c|}{$\begin{array}{l}\text { Local } \\
\text { Parque Estadual dos Três Picos }\end{array}$} & \multirow{2}{*}{\multicolumn{5}{|c|}{ Responsáveis técnicos: }} & \multicolumn{3}{|c|}{ Folha $n^{\circ}$} \\
\hline & & & \multicolumn{5}{|c|}{ Trilha } & & & & & & \multicolumn{3}{|l|}{ Data } \\
\hline \multicolumn{5}{|c|}{ Características físicas da trilha } & \multicolumn{11}{|c|}{ Impactos atuais do uso da trilha } \\
\hline \multirow{2}{*}{\multicolumn{3}{|c|}{$\begin{array}{c}\text { Distância: } \\
\text { UTM: }\end{array}$}} & \multirow{2}{*}{\multicolumn{2}{|c|}{ Nº. seção: }} & \multirow{2}{*}{\multicolumn{11}{|c|}{ Obs.: }} \\
\hline & & & & & & & & & & & & & & & \\
\hline \multirow[t]{2}{*}{ Lrg } & \multirow[t]{2}{*}{ Dpl } & \multirow[t]{2}{*}{ Dpp } & \multirow[t]{2}{*}{ Alt } & \multirow[t]{2}{*}{ Nbi } & \multirow[t]{2}{*}{ SE } & \multirow[t]{2}{*}{$\mathrm{CV}$} & \multirow[t]{2}{*}{ AR } & \multirow[t]{2}{*}{ Lit } & \multirow[t]{2}{*}{$\mathbf{L x}$} & \multirow[t]{2}{*}{ Vd } & \multicolumn{3}{|c|}{ Er } & \multirow[t]{2}{*}{ Dre } & \multirow[t]{2}{*}{$\mathrm{CA}$} \\
\hline & & & & & & & & & & & Lat & Lam & Sc & & \\
\hline & & & & & & & & & & & & & & & \\
\hline
\end{tabular}

QUADRO 1: Ficha de campo de caracterização ambiental.

Fonte: Ikemoto (2008), adaptado de Costa (op. cit.)

Para a determinação do grau de dificuldade, foi escolhido o critério da rampa média ao longo do trecho principal, elaborado por Rocha et al. (2006), sendo consideradas as seguintes classes: Leve (0 10\%); Média (10 - 20\%), Difícil (20 - 50\%), Muito difícil (50 - 100\%) e Alpinismo (> 100\%). Para a análise do design da trilha quanto ao perfil de usuários, foram utilizados os parâmetros estabelecidos por Lechner (2006).

\subsection{Caracterização da trilha quanto à Interpreta- ção Ambiental}

Levando em consideração as características locais e os objetivos da UC, a trilha do Jequitibá foi caracterizada, através de observação em campo, quanto a:

- Temática: presença de eixo temático, tópicos e a condução da interpretação (introdução, desenvolvimento e conclusão);

- Pontos interpretativos: caracterização qualitativa dos pontos;

- Presença ou não de recursos interpretativos variados: conteúdo, clareza, harmonia com o meio, acessibilidade, relevância;

- Sinalização (placas e painéis): conteúdo, clareza, acessibilidade, harmonia com o meio, relevância. 
- Modalidade: guiada, auto guiada ou guiada com outras programações;

- Diferenciação: grau de oferta de atividades para vários tipos de públicos-alvos.

- Atualização: se há e qual a periodicidade da reformulação ou aprimoramento dos temas interpretativos.

A partir do levantamento de campo, também foi avaliado se a trilha do Jequitibá é plenamente interpretativa segundo os princípios de Tilden (op. cit.) para a Interpretação Ambiental.

\subsection{Avaliação do Potencial Interpretativo da Trilha}

O Índice de Atratividade dos Pontos Interpretativos (IAPI), elaborado por Magro e Freixêdas (1998), é um método que busca facilitar a definição de pontos de interpretação ao longo de trilhas com fins educativos e interpretativos, principalmente naquelas que possuem vários pontos com características semelhantes. No presente estudo, a metodologia do IAPI foi adaptada de forma a ser aplicada em trilhas interpretativas já implantadas, a fim de caracterizá-las, avaliar as formas da condução da visitação e levantar os atrativos e as temáticas interpretativas.

O estudo exploratório inicial da trilha através do levantamento de suas características e o pré-levantamento de seus atrativos fundamentou a seleção dos “indicadores de atratividade”. Para a trilha do Jequitibá, foram selecionados os seguintes indicadores:

a) Proximidade (primeiro plano, médio plano e pano de fundo): consideraram-se os elementos que permitiam ao visitante contato direto ou toque como em primeiro plano; próximos ao leito da trilha, mas sem contato direto ou toque como em médio plano; e elementos distantes do leito da trilha como em pano de fundo.

b) Espaço disponível: representa quantas pessoas a trilha comporta em determinado atrativo, sem que se prejudique a qualidade de uma visita guiada. c) Visibilidade (inferior, médio e superior): este indicador refere-se à posição do atrativo em relação aos olhos do observador.

d) Estímulos sensoriais: consideraram-se os estímulos visuais, auditivos, táteis e olfativos que os atrativos proporcionam.

Elaborou-se uma ficha de campo própria para a trilha em estudo (QUAD. 2), na qual os pesos dos indicadores foram determinados consensualmente entre a pesquisadora e os condutores do Parque, e os valores de atratividade de cada elemento (Ó) resultam da multiplicação do peso com a intensidade ou abundância relativa do atrativo ( 1 = presente, 2 = grande quantidade e 3 = predominante). O elemento era presente, quando pouco expressivo quantitativamente e visualmente; relevante ou abundante quanto sua amostra era significativa quantitativamente ou se destacava visualmente; e predominante quando dominava e se destacava expressivamente na paisagem local. A soma total (ÓTt) corresponde ao valor da atratividade de um ponto interpretativo, ou seja, a soma da atratividade dos elementos presentes em um mesmo local ou em uma mesma distância.

O IAPI foi aplicado nos funcionários que conduziam visitas guiadas, de forma a avaliar as formas e a qualidade da visitação e Interpretação Ambiental realizada pela equipe da Unidade. O IAPI também foi aplicado a uma equipe externa composta por acadêmicos (dois geógrafos e dois biólogos) não ligados ao PETP, buscando comparar diferentes visões e possibilidades de condução dos visitantes. Assim como realizado por Costa (op . cit), foram mensuradas as distâncias dos pontos de atratividade em relação ao início da trilha, inventariados os recursos ambientais e culturais, e avaliados possíveis temas voltados à Interpretação Ambiental a serem aplicados para cada ponto, subsidiando a elaboração do inventário interpretativo.

Os atrativos levantados no IAPI foram ordenados através de uma adaptação do método de ranqueamento (Albuquerque e Guimarães, 2004) para determinar quais são as classes de atrativos existentes e quais mais se destacam dentro da trilha a partir da percepção dos observadores (guias e acadêmicos), fornecendo subsídios para a escolha de atrativos ou espé- 


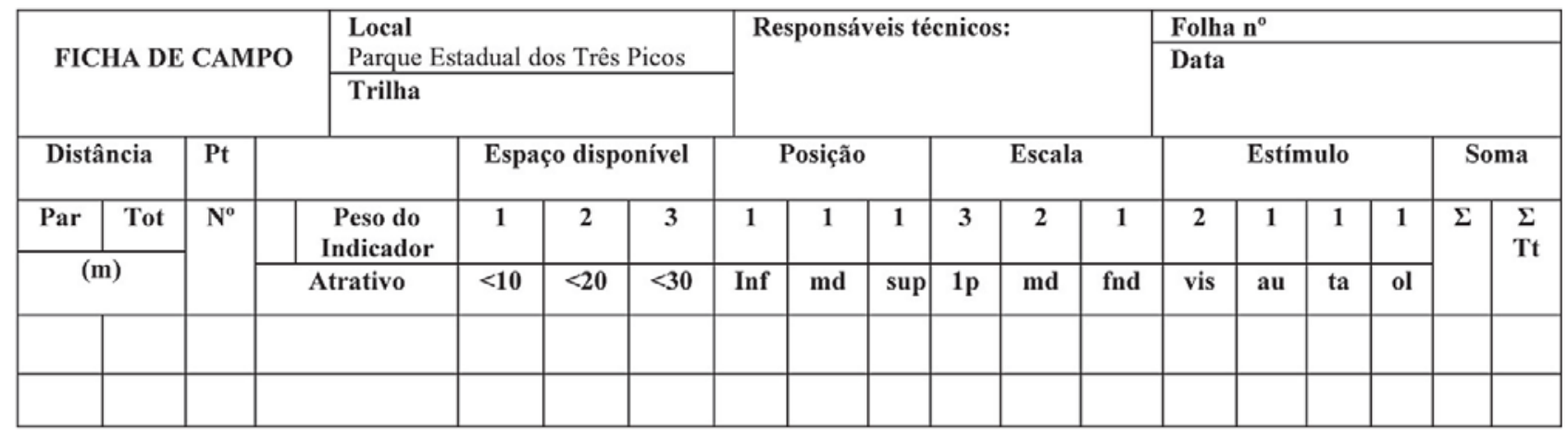

QUADRO 2: Ficha de campo do IAPI. Legenda: Pt- ponto, Par- distância parcial, Tot- distância total; Inf- inferior, Md- médio, Sup- superior; 1p- primeiro plano, md- médio plano, fnd- plano de fundo; Vis- visual, Au- auditivo, Ta- tátil, Ol- olfativo; Ó-soma , ÓTt- soma total. Os pesos são multiplicados pela intensidade do atrativo, onde 1= presente; 2=grande quantidade; $3=$ predominante Fonte: Ikemoto (2008), adaptado de Costa (op. cit.)

cies símbolos da UC. Os atrativos inventariados foram agrupados em categorias em função da espécie ou similaridade, ordenadas em ordem decrescente em função da atratividade total. A atratividade total corresponde à soma do valor de atratividade (Ó) atribuído pelos observadores aos atrativos da categoria.

\section{RESULTADOS}

\subsection{Caracterização biofísica da trilha do Jequitibá}

Segundo relatos dos moradores locais e dos próprios funcionários, a trilha já existia muito antes da criação do PETP, sendo frequentemente visitada em função do jequitibá-rosa (Cariniana legalis Mart.) e intensamente impactada pela ausência de manejo e manutenção. O PETP atualmente desenvolve atividades de implantação, manejo e monitoramento das trilhas, que têm alcançado bons resultados. Entre as principais ações desenvolvidas observadas, pode-se citar: alteração do traçado de forma a minimizar os impactos provocados pelo uso da trilha; limpeza e manutenção periódica do corredor; medição do grau de erosão; confecção e manutenção de drenos e canaletas e o nivelamento da trilha através da implantação de degraus de madeira reaproveitada.

Atualmente, a trilha possui a média de quatro drenos a cada 100 metros e não possui sinais de erosão laminar, lateral ou em sulcos, sendo o piso recoberto e protegido por serrapilheira em toda sua extensão. Dessa forma, os impactos do uso da trilha podem ser considerados mínimos e/ou controlados. No entanto, verificou-se a incidência de vandalismo dos últimos 10 metros da trilha, com destaque para as pichações e gravação de nomes nas árvores adultas adjacentes à trilha e no próprio jequitibá-rosa.

A trilha do Jequitibá é, segundo a classificação de Andrade (2004, p. 248), uma trilha linear, ou seja, o caminho da ida é o mesmo da volta, sendo por isso menos atrativa e exposta aos impactos da visitação mais intensos. O percurso passa por terrenos pouco ondulados e de baixa altitude, variando entre 410 a 430 m (FIG. 2), cuja largura média do piso é de 1,02m. O tempo médio de percurso guiado é de 40 minutos, num percurso total de 580m (ida e volta). Possui extensão total de 290m, declividade paralela máxima de $15^{\circ}$ e perpendicular máxima de $11^{\circ}$, sendo tanto a declividade paralela média e perpendicular média inferior a $7 \%\left(4,1^{\circ}\right.$ e $3,3^{\circ}$, respectivamente). Segundo o parâmetro da rampa média, portanto, é considerada como uma trilha leve, uma vez que possui declividade inferior a 10\%. A trilha é apropriada para pedestres, mas inadequada para cadeirantes e para outros tipos de uso segundo Lechner (2006).

A trilha do Jequitibá, portanto, devido à adequação quanto ao design, ao baixo nível de dificuldade e riscos, a curta distância, ao rápido tempo de percurso e aos impactos ambientais mínimos e devidamente controlados, pode ser considerada como biofisicamente adequada para a Interpretação Ambiental e a visitação em geral. 


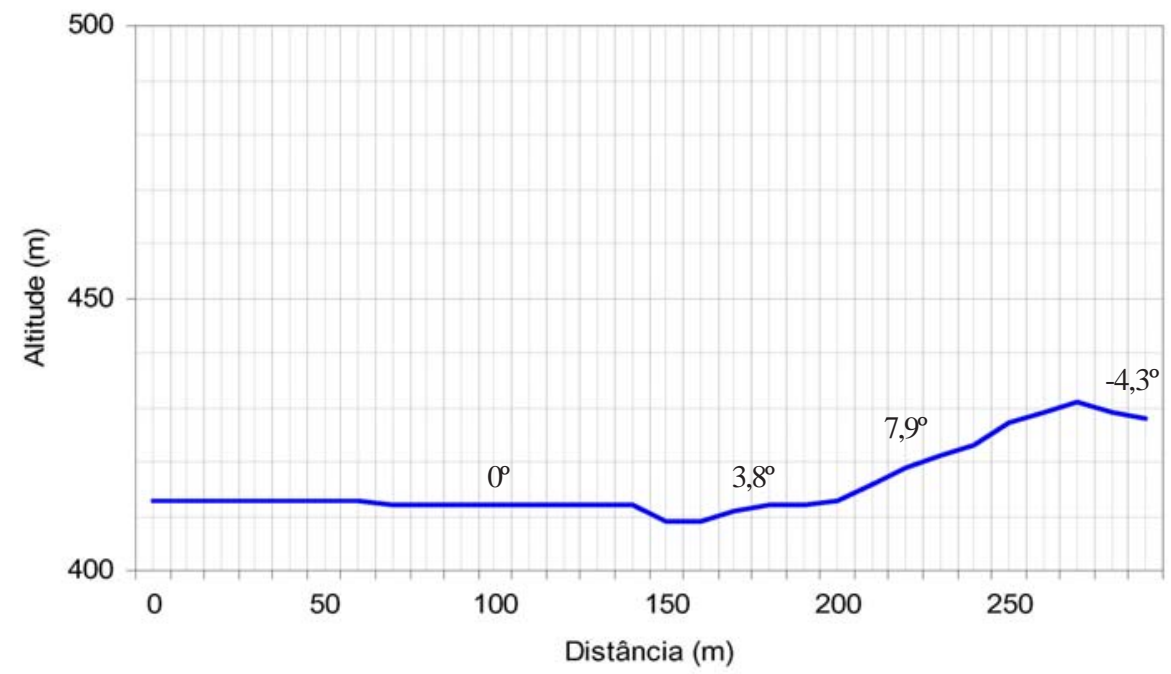

FIGURA 2: Perfil topográfico da trilha do Jequitibá. Os números indicados em graus foram obtidos a partir da média da declividade paralela num mesmo trecho da trilha.

Fonte: Ikemoto (2008).

\subsection{Quanto à Interpretação Ambiental}

A trilha do Jequitibá apresenta cinco pontos de interpretação delineados, marcados pela presença de placas informativas e do alargamento do corredor da trilha.

- Primeiro ponto (entrada): há, nesse local, uma placa que indica o percurso, a distância, duração e os atrativos da trilha, além de dar recomendações de conduta em áreas naturais protegidas (FIG. 3A).

- Segundo ponto: é marcado pela placa "Solo", que descreve o processo de formação dos solos e da dinâmica da vida existente no mesmo, e um terrário, que representa o modelo da estratificação do solo (FIG. 3B).

-Terceiro ponto: é marcado pela presença de um riacho que atravessa perpendicularmente a trilha, e a placa "ciclo hidrológico", que descreve a importância das matas ciliares para a integridade dos rios, esquematizando o ciclo da água (FIG. 3C).

- Quarto ponto: é marcado pela presença da placa "Formações rochosas" e uma gruta (FIG. 4A). A placa conceitua o que é rocha, descreve o seu processo de formação, discorre sobre as plantas rupícolas e caracteriza os tipos de rochas presentes na trilha.

- Quinto ponto: é marcado pela presença de espécime de jequitibá-rosa (Cariniana legalis Mart.), estimado em 1000 anos de idade, com aproximadamente 40 metros de altura e 19 metros de circunferência na base do tronco (FIG. 4B), dados indicados por uma placa interpretativa próxima à árvore (FIG. 4C).

A trilha do Jequitibá é diversificada quanto a sua paisagem, apresentando recursos diferenciados como cursos d'água, rochas e o singular espécime de jequitibá. Além disso, as placas interpretativas e a infraestrutura rústica agregam atratividade e demarcam os pontos de interpretação. No entanto, alguns pontos de parada e interpretação devem ser readequados para comportar grupos de visitantes e escolas. O terceiro ponto (FIG. 3C) pode ser considerado crítico, uma vez que não há o alargamento da trilha, o que promove o pisoteio do leito do córrego (apesar de existir uma pinguela/ponte) e prejudica a visualização do intérprete.

Devido à presença das placas, a trilha pode ser 

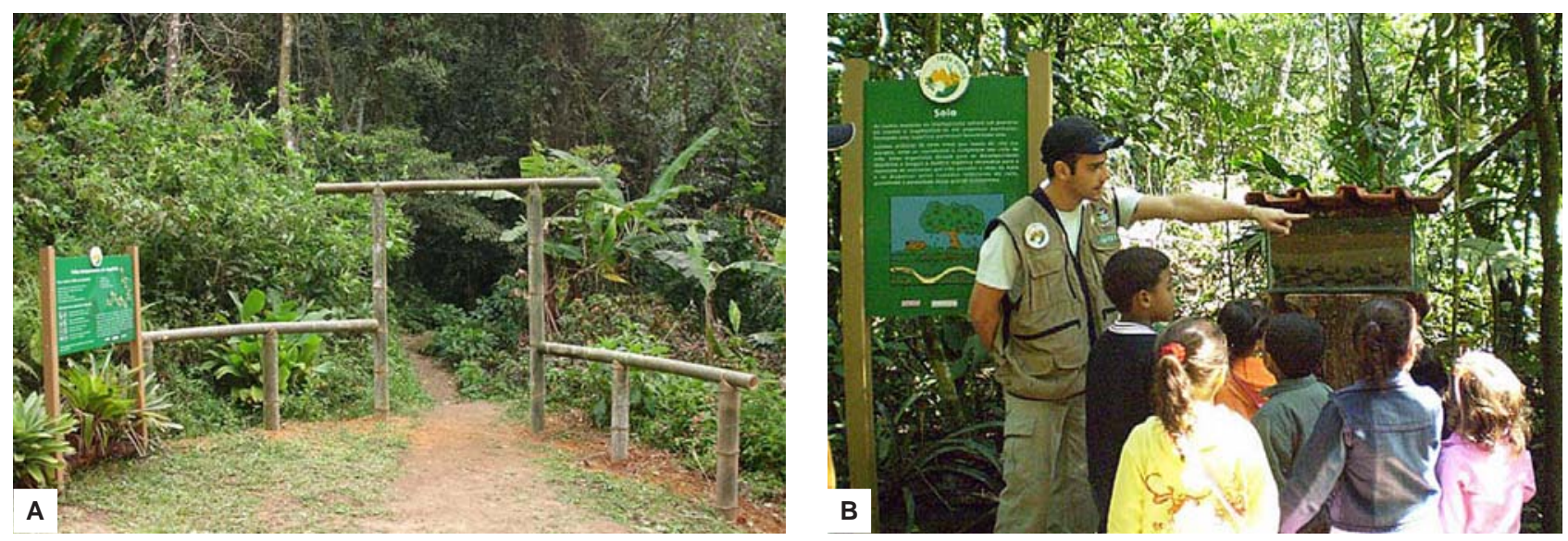

FIGURA 3: A. Entrada da trilha do Jequitibá indicada por um portal de bambu e placa interpretativa que oferece informações sobre a trilha e normas de visitação. B. Placa interpretativa sobre a formação do solo e sua importância para a floresta. Condutor interpretando o terrário. C. Córrego que atravessa perpendicularmente a trilha, placa interpretativa sobre o ciclo da água. Fotos: Silvia Marie Ikemoto, jul/2007.
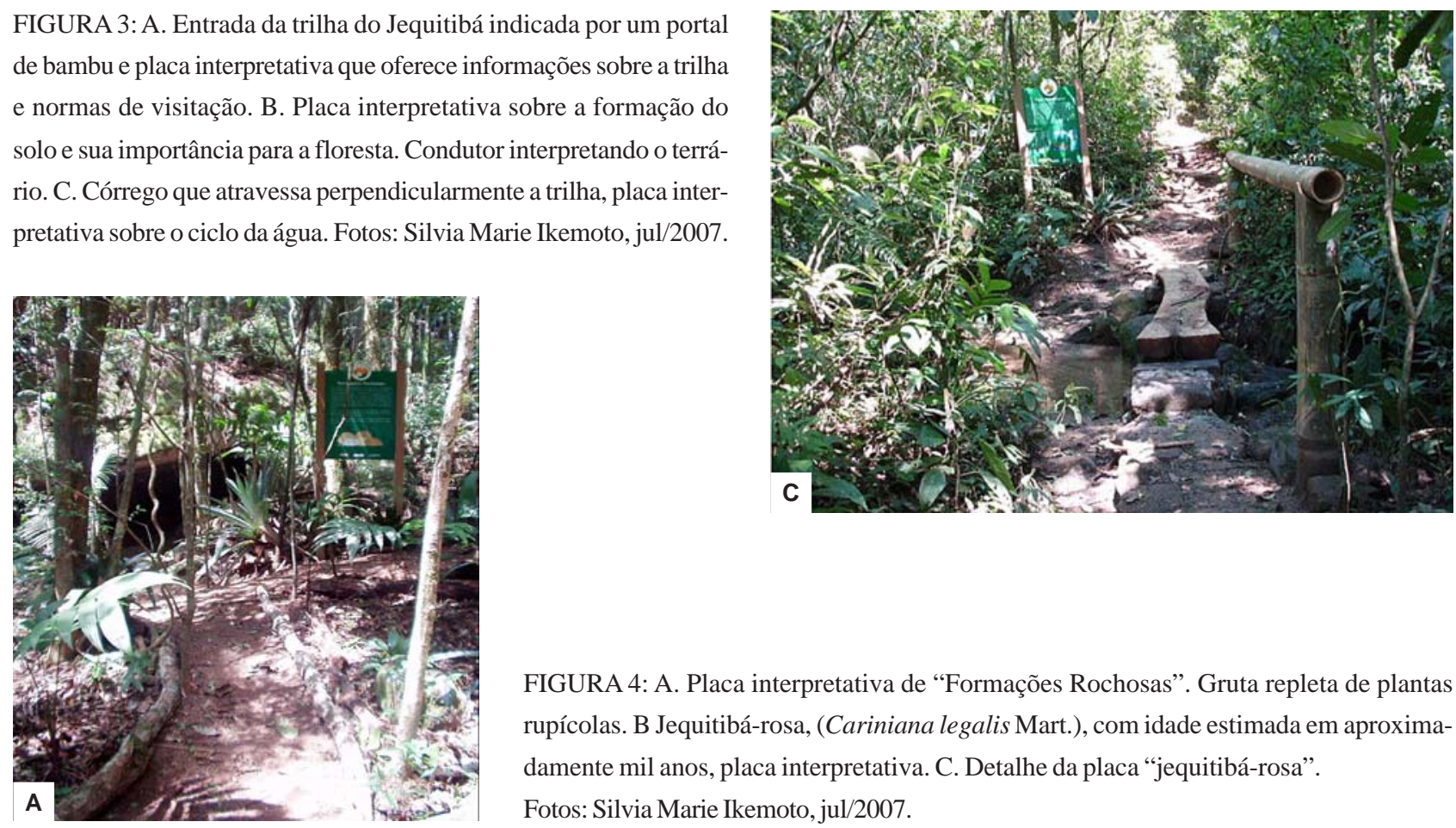

FIGURA 4: A. Placa interpretativa de "Formações Rochosas". Gruta repleta de plantas rupícolas. B Jequitibá-rosa, (Cariniana legalis Mart.), com idade estimada em aproximadamente mil anos, placa interpretativa. C. Detalhe da placa “jequitibá-rosa”. Fotos: Silvia Marie Ikemoto, jul/2007.
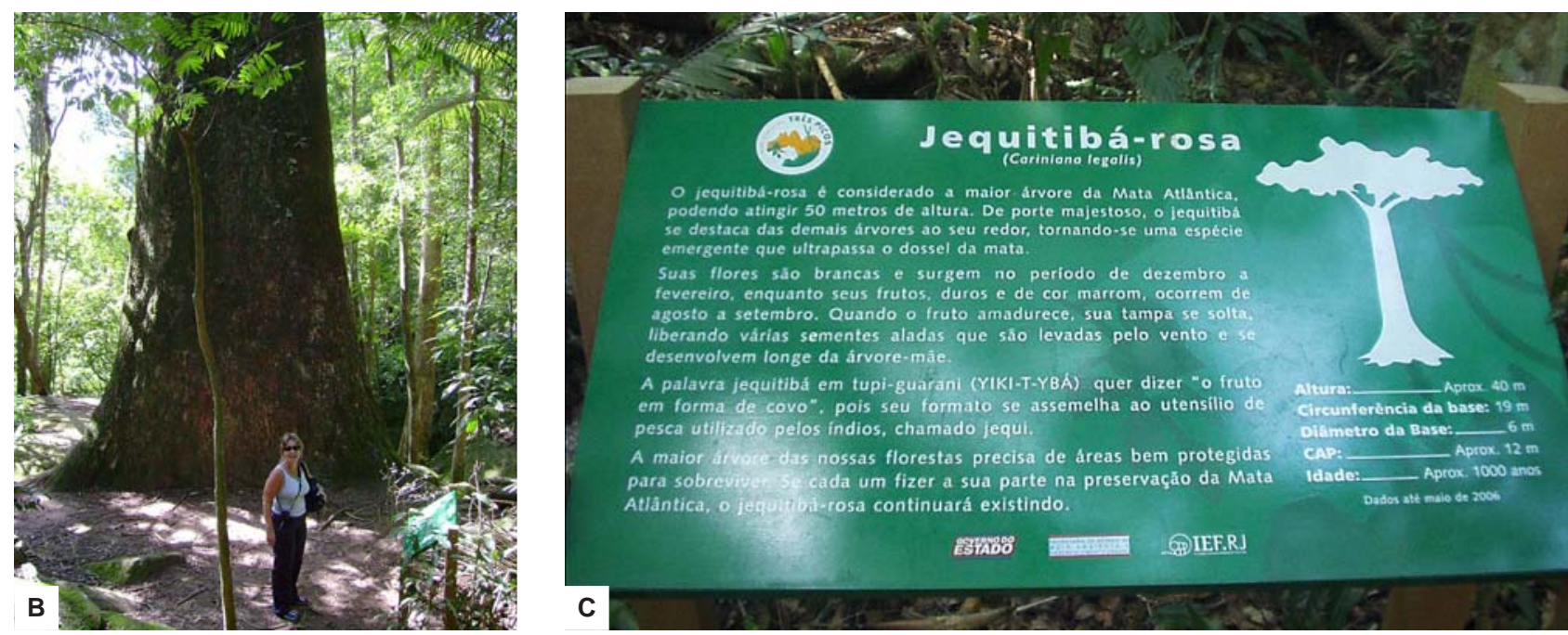

Sociedade \& Natureza, Uberlândia, 21 (3): 271--287, dez. 2009 
considerada tanto autoguiada quanto guiada, o que permite o uso da trilha por diferentes perfis de visitantes. No entanto, requer a presença de um intérprete de acordo com o perfil e grau de compreensão do visitante, uma vez que as informações disponibilizadas nas placas possuem linguagem técnica, se limitam a transmitir conteúdos ecológicos simplificados.

O intérprete ou educador, nesse contexto, deve preocupar-se em levantar questionamentos, perguntas e curiosidades, de forma a incitar a reflexão. Tópicos como aspectos socioeconômicos, históricos e culturais do parque; os serviços florestais prestados para a sociedade; potencial medicinal da flora do PETP, entre outros pontos de conexão do conhecimento ambiental com o cotidiano do visitante devem ser melhor explorados.

Quanto à sinalização, as placas são padronizadas, de cores suaves e em altura e angulação que tornam a leitura fácil e acessível. As trilhas, bem manejadas e de baixo nível de dificuldade, permitem o uso do público de todas as idades. No entanto, no caso de portadores de necessidades especiais, a sinalização em Braille e a acessibilidade das trilhas para cadeirantes ainda não estão disponíveis. O grau de oferta de atividades para diferentes públicos é baixo, pois há pouca oferta de roteiros de visitação guiada ou autoguiada que atendam públicos diferenciados, tais como pessoas portadoras de necessidades especiais, público infantil e grupos acadêmicos.

Apesar das instalações turísticas e manejo biofísico adequados, a atividade desenvolvida pelo PETP, portanto, não pode ser considerada como plenamente interpretativa, uma vez que não atende parte dos princípios da IA segundo Tilden (1977), devendo buscar explorar mais recursos educativos, estabelecer mais relações entre o que está sendo interpretado e o cotidiano do visitante, utilizar linguagem clara e acessível e oferecer atividades diferenciadas em função do público alvo.

\section{3. Índice de atratividade dos pontos interpre- tativos (IAPI)}

De forma a descrever e avaliar a atividade interpretativa desenvolvida pelo PETP e o potencial interpretativo da trilha, a partir dos dados levantados pela ficha de campo do IAPI, a FIG. 5 apresenta um gráfico que representa o valor de atratividade dos pontos interpretativos (representado por ÓTt) atribuído por cada observador em função da distância percorrida na trilha, e a tabela 2, na qual os atrativos estão apontados e ordenados em categorias em função do valor de atratividade (soma de Ódos atrativos de determinada categoria).

A partir da análise da FIG. 5, é possível inferir que existe um roteiro consensual de interpretação, uma vez que os pontos interpretativos pré-estabelecidos nas trilhas (ponto 1 ao 5) obtiveram unanimemente os maiores valores de atratividade e foram citados por todos os observadores (intérpretes) e pelo grupo acadêmico. Os altos valores de atratividade podem ser associados não só aos recursos naturais existentes, como às intervenções realizadas (inserção das placas, alargamento da trilha, pinguela) que contribuem para minimizar a homogeneidade da paisagem e/ou agregam informações. No entanto, as diferenças entre os valores de atratividade atribuídos por cada observador para um mesmo ponto foram significativas, (tais como os pontos 2, 4 e 5) o que indica que, apesar do consenso, há uma multiplicidade de abordagens e o subaproveitamento dos atrativos por alguns condutores. No ponto 4, enquanto alguns abordavam somente a gruta e a placa de formações rochosas, outros observadores também indicaram as plantas rupícolas e epífitas e a sua interação com a fauna e o ambiente, a dinâmica da sucessão secundária a partir dos monjolos, entre outros, atribuindo altos valores de atratividade nesse ponto.

No ponto 5, além do jequitibá-rosa e a placa interpretativa, alguns observadores apontaram troncos agredidos e riscados, a partir do qual trabalhariam a conscientização contra essa prática, abordariam a questão histórica da destruição da floresta a partir do jequitibá, atingindo os maiores valores de atratividade. Ou seja, é possível inferir que a atratividade de um determinado ponto está relacionada não só aos recursos naturais e intervenções, como também na forma que o condutor aborda seus atrativos com diferentes temáticas e assuntos, explorando seu potencial.

Apesar de existir um consenso sobre os pontos interpretativos pré-definidos (pontos 1 ao 5), podese perceber uma variação e a identificação de inúme- 


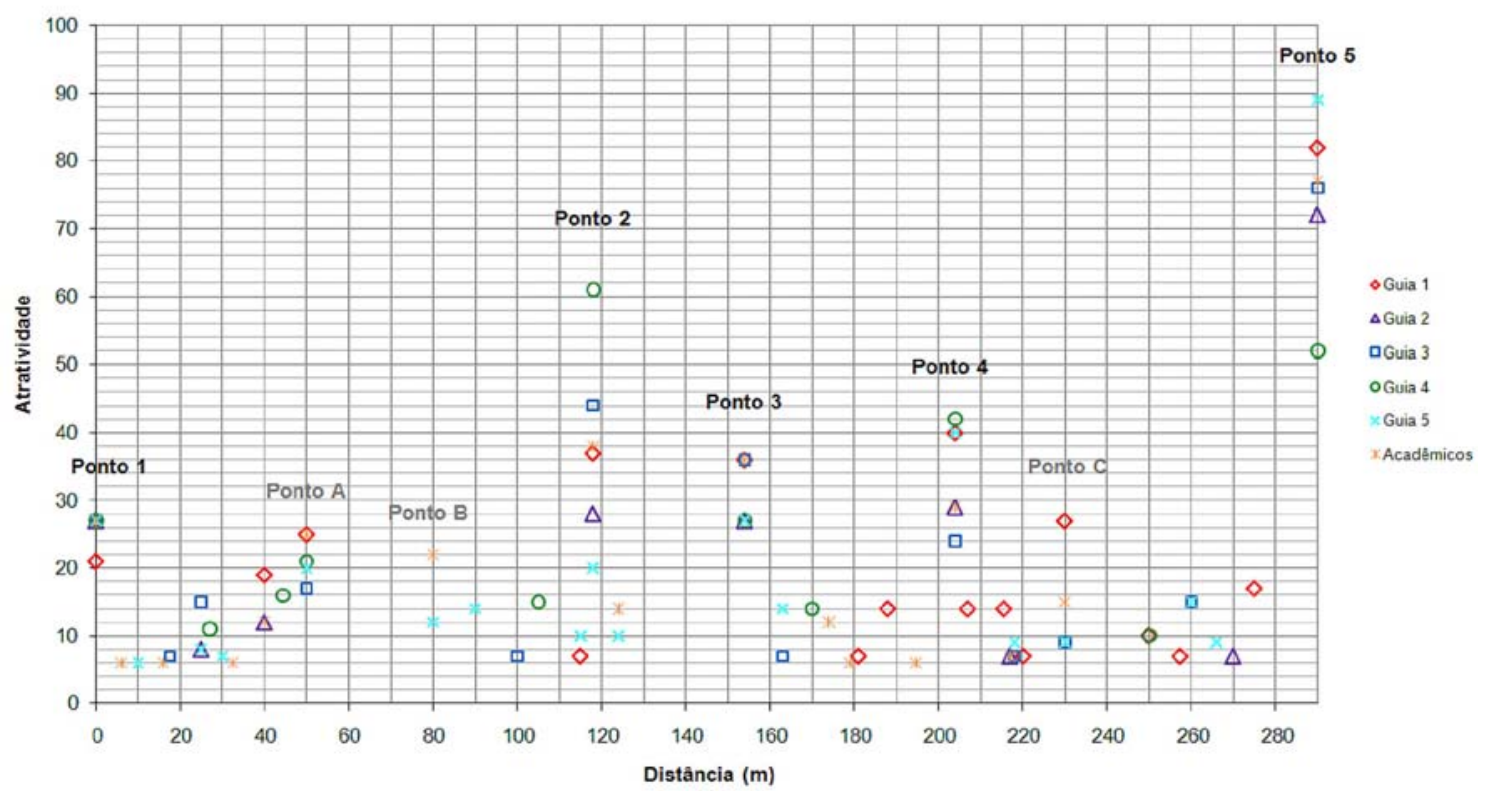

FIGURA 5: Índice de atratividade dos pontos interpretativos em função da distância. A atratividade foi obtida através da metodologia do IAPI. Pontos interpretativos delineados pelo PETP. Ponto 1: Entrada da trilha e placa interpretativa. Ponto 2: Córrego e placa sobre o “Ciclo da Água”. Ponto 3: Terrário e Placa sobre os “Solos”. Ponto 4: Gruta e placa sobre “Formações Rochosas”. Ponto 5: Jequitibárosa de aproximadamente 1000 anos e placa interpretativa sobre o mesmo. Pontos alternativos apontados pelos observadores (guias e acadêmicos). Ponto A: Irizeiro e Cedro-rosa sobre pedra. Ponto B: Monjolos. Ponto C: Escadaria cercada de importantes árvores da Mata Atlântica.

Fonte: Ikemoto, 2008.

ros outros atrativos entre os guias. Os pontos A, B e C, por exemplo, são considerados altamente atrativos por alguns observadores, e poderiam ser explorados como pontos consensuais e alternativos de interpretação pelos condutores do PETP.

Pela diversidade de temas abordados pelos observadores no IAPI, é possível inferir que não há uma organização temática da Interpretação. Os assuntos são abordados isoladamente pelos funcionários do PETP, de forma aleatória, sem haver necessariamente uma interconexão entre os mesmos e uma ideia central dotada de significado. Apesar da grande riqueza de atrativos e as relevantes temáticas apontadas, sem a adoção de um tema norteador, a Interpretação fica limitada à transmissão de conteúdos, informações e curiosidades sobre o local e seus diversos recursos. $\mathrm{Ou}$ seja, embora sejam agregados alguns valores sobre a proteção ambiental, as informações são trabalhadas de maneira fragmentada e desassociada do cotidiano do visitante.

A escolha do tema de interpretação de uma trilha é fundamental, já que este define e direciona o conteúdo que será abordado, relacionando as diversas informações em uma mensagem principal, tornando a atividade significativa e clara ao público. Para Ham (1992), os conteúdos devem ser trabalhados em cada ponto de parada de tal forma que, ao final da trilha, os visitantes saibam ou entendam algo. Por exemplo, ao definir o tema "Floresta: um sistema integrado" é possível trabalhar os diversos componentes da trilha (solo, água, fauna, flora, homem) e suas inter-relações, objetivando demonstrar ao final da atividade interpretativa que a floresta é um sistema integrado, onde a interferência ou a degradação de um desses componentes levará ao comprometimento de todo o conjunto. Por sua vez, o tema "A importância da floresta 
para o homem" daria enfoque aos serviços ambientais da mata ciliar e da cobertura vegetal, além dos diversos usos possíveis dos recursos florestais (ritualístico, tecnológico, alimentício, medicinal, etc.), objetivando demonstrar a importância da proteção das áreas naturais ao ser humano. A definição de roteiros foge ao escopo deste trabalho, uma vez que deve estar incluída dentro de um Plano de Interpretação Ambiental do PETP.

A TAB. 1 indica, por ordem decrescente, a relevância e o potencial para a Interpretação Ambiental das categorias de atrativos. Destacaram-se o jequitibá rosa, gruta e rochas, riacho, terrário, placa interpretativa de entrada, espécies florestais como o monjolo, irizeiro, cedro-rosa, palmito Jussara e plantas epífitas e rupícolas.

Os atrativos que não se encaixaram em ne- nhuma das categorias anteriores e foram citados somente uma vez estão agrupados na categoria “outros”, e reiteram a abordagem interpretativa não consensual e heterogênea entre os observadores.

Um dos fatos constatados através da tabela 1 é que a fauna praticamente não é explorada e valorizada na trilha do Jequitibá. Esse fato está associado a uma dificuldade geral de explorar o tema devido à distribuição pulverizada dos animais no ambiente, a susceptibilidade da fauna a ruídos e a necessidade de desenvolvimento da percepção do visitante para "visualizá-la”. Isso não impede, no entanto, que se trabalhe indiretamente a temática. Entre algumas das alternativas, é possível explorar os sons e rastros, além de trabalhar as interações fauna-flora e fauna-ambiente nas trilhas.

TABELA 1: Ordenamento da categoria de atrativos segundo o valor de atratividade total atribuído pelos obser-vadores (condutores e acadêmicos).

\begin{tabular}{lcc}
\hline Categoria de Atrativo & $\mathbf{N}^{\mathbf{0}}$. de citações & Atratividade total \\
Jequitibá-rosa & 23 & 383 \\
Rochas e grutas & 10 & 200 \\
Riacho/córrego & 7 & 174 \\
Terrário & 9 & 159 \\
Entrada (placa interpretativa) & 5 & 135 \\
Pau-jacaré ou monjolo & 11 & 95 \\
Irizeiro & 8 & 77 \\
Cedro-rosa & 7 & 72 \\
Manutenção de trilhas & 13 & 63 \\
Epífitas e rupícolas & 7 & 59 \\
Paineiras & 5 & 46 \\
Jussara & 4 & 37 \\
Jaqueira & 4 & 31 \\
Jequitibá-branco & 3 & 27 \\
Figueira mata-pau & 3 & 27 \\
Barata d'água & 3 & 26 \\
Rabo de Galo & 7 & 23 \\
Observação da fauna & 3 & 23 \\
Cambuí & 3 & 22 \\
Angico & 3 & 19 \\
Urtiga & 2 & 14 \\
Bromélias & 2 & 12 \\
Outros & 23 & 207 \\
\hline Fonte: & &
\end{tabular}

Fonte: Ikemoto (2008) 
Os temas de cunho sócio cultural foram pouco explorados e valorizados, sendo enfatizados conteúdos ligados à flora e ao meio físico. Numa trilha interpretativa, é extremamente importante ter o cuidado de não se limitar aos aspectos biofísicos das trilhas, abordando também questões históricas e culturais de forma a buscar associar o conteúdo ao cotidiano do ouvinte. Recursos sonoros, táteis e olfativos, apesar de existentes, foram pouco citados e valorizados quanto a sua atratividade, o que demonstra a falta de percepção dos guias e observadores para explorar a temática sensorial, que, além de estimular e enriquecer a experiência do visitante, possibilita o trabalho com portadores de necessidades especiais.

Por outro lado, tanto a abordagem do intérprete quanto a percepção do visitante restringem-se muitas das vezes àquilo que é prontamente visualizável, sendo necessário readequar a escala de observação dos elementos e fenômenos para a IA. É possível explorar e valorizar não só os organismos de médio e grande porte, como também os elementos e fenômenos de menor escala. A interação entre as formigas e a embaúba, a relação entre os fungos e o surgimento das galhas são alguns tópicos que demonstram possibilidade e a relevância de se trabalhar com a interpretação em micro-escala na trilha do Jequitibá, podendo aguçar a percepção do observador e desenvolver no mesmo o senso de explorar e descobrir o ambiente. Dessa forma, maior atenção deve ser dada às referidas temáticas para que as mesmas possam ser exploradas no PETP de forma a potencializar a Interpretação Ambiental na trilha do Jequitibá.

A partir das temáticas interpretativas e atrativos apontados pelos observadores no IAPI, elaborouse ainda o inventário interpretativo da trilha do Jequitibá, disponível em Ikemoto (2008), que pode ser utilizado pela equipe do PETP como base para a elaboração de roteiros temáticos múltiplos.

A totalidade de dados e informações geradas pelo IAPI subsidiaram a elaboração da apostila "Sugestões de atividades educativas e interpretativas na trilha do Jequitibá", com a finalidade de traduzir os resultados do presente trabalho em linguagem mais objetiva e acessível para guias, funcionários da UC e professores de forma a amenizar a carência de informações e a incentivar a promoção da IA. O documen- to também foi elaborado como uma forma de facilitar a aplicabilidade e o retorno das informações para a sociedade, sendo cedido ao PETP e ao IEF.

\section{Considerações finais}

Através da metodologia do IAPI, foi possível compilar um amplo leque de atrativos e temas de condução, resultando em um inventário interpretativo, e através dos valores obtidos, selecionar com maior embasamento os pontos de parada e/ou interpretação e avaliar a atividade interpretativa realizada pelo PETP. Além disso, a técnica permitiu a contribuição de pessoas com experiência em condução e membros externos de diversas formações, constituindo uma equipe multidisciplinar de observadores, mostrando-se eficaz e utilitária para o planejamento da IA.

Apesar do PETP oferecer atividades como palestras, passeios em trilhas e outras atividades recreativas ou educativas, essas, na maior parte das vezes, não estão organizadas em torno de um tema interpretativo, portanto, a Interpretação fica limitada à transmissão de conteúdos, informações e curiosidades sobre o local e seus diversos recursos. $\mathrm{O}$ alto índice de atratividade e a expressiva quantidade de pontos de interpretação, apontados pelo IAPI, devem ser aproveitados, dessa forma, na elaboração de roteiros diferenciados e temáticos (com poucos, mas relevantes pontos interpretativos) que poderão ser alternados, explorados de múltiplas formas e atualizados. Para isso, é essencial que guias e condutores do PETP sejam capacitados de forma a conhecer as múltiplas formas de abordagem da trilha em questão, enriquecendo a IA e minimizando possíveis incoerências e informações desconexas entre diferentes intérpretes.

Intervenções e recursos de baixo custo podem contribuir no atendimento a tipos diferenciados de público. Roteiros temáticos adaptados, como a interpretação através dos recursos sensoriais da trilha e a presença de estruturas de orientação/guia, tais como cordas ou meio-fios, são adaptações simples que podem ser exploradas na trilha do Jequitibá de forma a promover a acessibilidade. A utilização de materiais alternativos como binóculos e lupas, a elaboração e uso de guias de campo, e o desenvolvimento de atividades lúdicas tais como a contação de histórias, dinâmicas e 
músicas são exemplos de recursos educativos que podem ser facilmente explorados de forma a enriquecer a vivência e estimular o visitante.

Apesar de não atender a todos os princípios da IA, a trilha do Jequitibá pode ser considerada uma trilha com caráter e potencial interpretativo, no entanto, os pontos frisados devem ser trabalhados de forma a implementar e desenvolver plenamente a Interpretação Ambiental. $\mathrm{O}$ fato das trilhas não serem consideradas plenamente interpretativas não significa que impede que as mesmas cumpram, mesmo que parcialmente, função social quanto à conscientização e sensibilização. Significa, na realidade, que o potencial da trilha como instrumento de Educação Ambiental é parcialmente explorado.

As trilhas interpretativas, enquanto um produto turístico e meio educativo, devem ser fundamentadas num conhecimento confiável, preciso e integrado. A diversidade da vegetação e a presença de espécies de relevância econômica e medicinal são potenciais atrativos das trilhas, no entanto, não há um levantamento oficial da flora do entorno das trilhas do PETP, não estando catalogadas, ou muito menos identificadas e sinalizadas, as relevantes espécies vegetais ali presentes. Não há como dissociar a Interpretação Ambiental de outras práticas relacionadas ao plano de uso público da Unidade de Conservação. Por exemplo, um projeto de instalação turístico adequado (infraestrutura, acesso e serviços) reflete no projeto de visitação (Interpretação Ambiental), que estarão auxiliando conjuntamente na conservação de valorização dos recursos naturais e culturais, enriquecendo a experiência do turista. A estruturação de programas de visitação devem também contemplar a avaliação dos impactos desta prática, definindo a capacidade de suporte da área natural e avaliando os impactos e os efeitos da visitação no espaço natural. Dessa forma, levantamentos das principais espécies vegetais de potencial interpretativo presente no entorno das trilhas, a avaliação do Programa de Uso Público e estudos de capacidade de carga e da infra-estrutura turística são exemplos de demandas que necessitam ser contempladas em outros estudos.

A partir das discussões, análises e dados gerados, espera-se ter contribuído para o enriquecimento da literatura sobre a utilização das trilhas como instru- mento educativo e pedagógico e para valorização dos programas de IA em Unidades de Conservação, práticas recentes, ainda incipientes, mas progressivamente reconhecidas perante suas contribuições. Em específico, ao Parque Estadual dos Três Picos, por fornecer subsídios para que se promovam ações no aprimoramento da Interpretação Ambiental.

\section{REFERÊNCIAS}

ALBUQUERQUE, U. P.; GUIMARÃES, R. F. P. L. Métodos e técnicas para coleta de dados. In: ALBUQUERQUE, U. P. \& GUIMARÃES, R. F. P. L. (org). Métodos e técnicas na pesquisa etnobotânica. Recife: LivroRápido/NUPEEA, 2004. p. 37-62.

ANDRADE, W. J. Implantação e Manejo de Trilhas. In: MITRAUD, S. W. (org.) Manual de Ecoturismo de Base Comunitária: ferramentas para um planejamento responsável. Brasília: WWF - Brasil, 2004. p. 247-259.

BRASIL. Ministério do Meio Ambiente. Diretrizes para Visitação em Unidades de Conservação. Brasília: Secretaria de Biodiversidade e Florestas, Diretoria de Áreas Protegidas, 2006.

CAMPOS, R. M. O Parque Estadual dos Três Picos (PETP) e sua inserção no contexto da conservação da natureza no estado do Rio de Janeiro. 80 f. 2007. Monografia (Geografia), Universidade Federal Fluminense, Niterói, 2007.

CORRÊA, A. M. Módulo: iniciação a Interpretação Ambiental. Disponível em <http://www.sindegtur.org.br /2006/arquivos/a2.pdf > Acesso em 03 out. 2006.

COSTA, V. C. Propostas de manejo e planejamento ambiental de trilhas ecoturísticas: um estudo no Maciço da Pedra Branca - município do Rio de Janeiro (RJ). 325f. 2006. Tese (Doutorado em Geografia), Universidade Federal do Rio de Janeiro, Rio de Janeiro, 2006.

FRANCO, M. A. R. Ecoturismo em Parques Nacionais. In: FRANCO, M. A. R. Planejamento ambiental 
para a cidade sustentável. São Paulo: Annablume, FAPESP, 2000. p. 55-78.

HAM, S. H. Environmental Interpretation: a practical guide for people with big ideas and small budgets. Colorado: North American Press, 1992.

HANAI, F. Y.; NETTO, J. P. S. Instalações ecoturísticas em espaços naturais de visitação: meios para propiciar a percepção e a interpretação ambientais. OLAM Ciência \& Tecnologia, Rio Claro, v. 6, n. 2, p. 200-223, dez. 2006.

IKEMOTO, S. M. As trilhas interpretativas e sua relevância para promoção da conservação: Trilha do Jequitibá, Parque Estadual dos Três Picos (PETP), RJ. 170 f. 2008. Dissertação (Mestrado em Ciência Ambiental), Universidade Federal Fluminense, Niterói, 2008.

IRVING, M. A. A. Refletindo sobre o Ecoturismo em Áreas Protegidas - tendências no contexto brasileiro. In: IRVING, M. A.; AZEVEDO, J. (org.). Turismo: o desafio da sustentabilidade. São Paulo: Futura, 2002. p. 47-68.

LECHNER, L. Planejamento, Implantação e Manejo de Trilhas em Unidades de Conservação. Cadernos de Conservação. Fundação O Boticário de Proteção à Natureza, jun., ano 03, Curitiba, 2006.

LIMA, S. T. Trilhas Interpretativas: a aventura de conhecer a paisagem. Cadernos Paisagens. Rio Claro, Paisagem 3, n. 3, p. 39-44, mai. 1998.

MAGRO, T. C.; FREIXÊDAS, V. M. Trilhas: como facilitar a seleção de pontos interpretativos. Circular Técnica IPEF. Piracicaba, n. 186, p. 4-10, 1998.

PROJETO DOCES MATAS. Manual de Introdução à Interpretação Ambiental. Belo Horizonte: IEF IBAMA - Fundação Biodiversitas - GTZ, 2002.

RIO DE JANEIRO (Estado). Decreto Estadual $n^{\circ}$ 31.343 de 05 de junho de 2002. Cria o Parque Estadual dos Três Picos, no Estado do Rio de Janeiro, e dá outras providências. Disponível em: <http://www.ief.rj. gov.br/legislacao/docs/31343.doc>. Acesso em: 15 abr. 2007.

RIO DE JANEIRO (Estado). Decreto Estadual $n^{\circ}$ 41.990 de 12 de agosto de 2009. Amplia a área do Parque Estadual dos Três Picos e dá outras providências. Diário Oficial do Estado do Rio de Janeiro, Ano XXXV, n. 146, 13 de agosto de 2009, p. 1. Disponível em: http://www.imprenssaoficial.rj.gov.br. Acesso em: 15 jan. 2010.

ROCHA, C. H. B.; FONTOURA, L. M.; SIMIQUELI, R. F.; PEREIRA, G. M.; MANOEL, J. S. Mapeamento e classificação de trilhas em parques florestais com uso do GPS: aplicação no Parque Estadual de Ibitipoca /MG. In: Congresso Brasileiro de Cadastro Técnico Multifinalitário. Anais... Florianópolis, UFSC, 2006.

SHARPE, G. W. Interpreting the environment. New York: John Wiley, 1982.

SILVA, L. L. Ecologia: manejo de áreas silvestres. Santa Maria: MMA/FNMA/FATEC, 1996.

TAKAHASHI, L. Y. Capacidade de Suporte Recreativo em Unidades de Conservação - Novas Metodologias. In: $1^{\circ}$ Simpósio de Áreas Protegidas, Pelotas. Anais... Universidade Católica de Pelotas, 2001. p. 112-122.

TALORA, D. C.; DELGADO-MENDEZ, J. M; PIMENTEL, D. S.; MAGRO, T. C. A. Interpretação Ambiental como instrumento de gestão de Unidades de Conservação. In: I Congresso Nacional de Trilhas. Anais... Universidade Estadual do Rio de Janeiro, Rio de Janeiro, 2006. p. 1-15. CD-ROM

TILDEN, F. Interpreting our heritage. North Carolina: The University of North Carolina Press, 1977.

VASCONCELLOS, J. M. O. Avaliação da visitação pública e da eficiência de diferentes tipos de Trilhas Interpretativas do Parque Estadual Pico do Marumbi e Reserva Natural Salto Morato - PR. 1998. 88 f. Tese (Doutorado em Engenharia Florestal) - Setor de Ciências Agrárias, Universidade Federal do Paraná, Curitiba, 1998. 